\title{
O ACESSO À INFORMAÇÃO COMO INSTRUMENTO À EDUCAÇÃ̃O INCLUSIVA: UM OLHAR A PARTIR DO DESENVOLVIMENTO SUSTENTÁVEL
}

\section{ACCESS TO INFORMATION AS AN INSTRUMENT TO INCLUSIVE EDUCATION: A LOOK FROM SUSTAINABLE DEVELOPMENT}

\author{
Isadora Kauana Lazaretti* \\ Elouise Mileni Stecanella* \\ Yana Paula Both Voos*
}

Resumo: O presente trabalho tem como tema central os direitos fundamentais no que se refere ao acesso à informação como instrumento à educação inclusiva, a partir da perspectiva da Agenda 2030 da Organização das Nações Unidas (ONU). Para tanto, fora proposta uma análise acerca da Agenda 2030, bem como um estudo bibliográfico sobre o direito humano fundamental ao acesso à informação e seu impacto na educação. A pesquisa utilizou a técnica de pesquisa bibliográfica, por sua natureza exploratória, por meio da utilização de artigos da base de dados da CAPES, além da legislação brasileira, documentos internacionais oficiais e outros artigos e obras sobre a temática.

Palavras-chave: acesso à informação; Agenda 2030; desenvolvimento sustentável; educação inclusiva.

Abstract: This work focuses on fundamental rights regarding access to information as a tool for inclusive education, from the perspective of the United Nations (UN) Agenda 2030. To

\footnotetext{
* Doutoranda em Direitos Fundamentais pela Universidade do Oeste de Santa Catarina - UNOESC. Bolsista CAPES/PROSUC. Mestre em Direito pela Universidade Comunitária da Região de Chapecó - UNOCHAPECÓ. Currículo Lattes: http://lattes.cnpq.br/4070049769045027. E-mail: iklazaretti@gmail.com. Endereço postal: Rua Herculano H. Zanuzzo, 632, Bairro Industrial, Seara - SC.

* Mestranda em Direito pela Universidade Comunitária da Região de Chapecó - UNOCHAPECÓ. Bolsista CAPES. Especialista em Direito Civil e Empresarial pelo Damásio Educacional. Currículo Lattes: http://lattes.cnpq.br/4238863472745393. E-mail: elouise.mileni@gmail.com. Endereço postal: Rua Eloir José Cândido, n. 65, Bairro Luther King, Francisco Beltrão-PR.

* Mestranda em Direitos Fundamentais pela Universidade do Oeste de Santa Catarina - UNOESC. Bolsista CAPES/PROSUC. Especialista em Direito Penal e Criminologia pelo Centro Universitário Internacional. Currículo Lattes: http://lattes.cnpq.br/0931683734378259. E-mail: yanapaula04@ hotmail.com. Endereço postal: Rua General Osório, 598, Centro, Humaitá-RS.
} 
this end, an analysis of Agenda 2030 was proposed, as well as a bibliographical study about the fundamental human right to access to information and your impact on education. The research used the technique of bibliographic research, by its exploratory nature, through the use of articles from the CAPES database, in addition to Brazilian legislation, official international documents and other articles and works on the subject.

Keywords: access to information; Agenda 2030; sustainable development; inclusive education.

\section{INTRODUÇÃO}

Poucos conceitos como o de desenvolvimento sustentável tem aparecido com tamanha recorrência nas últimas décadas. A nível internacional, tornou-se pauta de agendas e políticas adotadas por muitos países na adoção de medidas básicas voltadas à garantia dos direitos humanos e fundamentais. Com o advento da Agenda 2030 da Organização das Nações Unidas, muitos Estados têm buscado agir de forma ousada e transformadora, trilhando um caminho sustentável e resiliente em vários aspectos, a fim de melhorar a qualidade de vida das pessoas no (e do) planeta.

Um desses aspectos, é a educação, cuja garantia e acesso pleno vem sendo influenciada pelo acesso à informação. Afinal, a informação gera capacidades de formalizar conhecimentos, além de constituir um empoderamento para a construção de uma cidadania consciente, e contribuir para um desenvolvimento sustentável.

Nesse sentido, este estudo tem como objetivo analisar como o acesso à informação pode ser visto como um instrumento à educação inclusiva no marco da Agenda 2030 da ONU. A escolha do tema e sua transformação em problemática investigativa se deu pela relevância atual, especialmente pelas mudanças provocadas pelo "novo normal" e a necessidade da utilização de instrumentos tecnológicos como requisito para se ter acesso à educação em tempos de pandemia em que todas as atividades de ensino passaram a ser ministrada por meio do ensino remoto e on-line.

Assim, o artigo foi dividido em três partes: a primeira, destina-se a estudar o conceito de desenvolvimento sustentável e a Agenda 2030 da ONU, a partir de um breve e necessário histórico de fatos que originaram esse debate; a segunda, volta-se para a compreensão do 
acesso à informação enquanto um direito humano e fundamental; e a terceira parte, o estudo se direciona a análise específica do acesso à informação como um instrumento de promoção e alcance para a educação inclusiva a partir dos Objetivos de Desenvolvimento Sustentável da Agenda 2030 da ONU.

A realização deste estudo teve por base a técnica de pesquisa bibliográfica, realizada com base na seleção de artigos específicos selecionados na base de dados da CAPES. Os termos utilizados para a busca foram "desenvolvimento sustentável", "Agenda 2030" e "educação", dos quais foram escolhidos aqueles mais específicos de acordo com o tema deste estudo, a partir da análise do título e do resumo. A pesquisa foi refinada para buscar tão somente artigos publicados em periódicos revisados por pares. Também foram utilizados outros artigos de interesse das autoras, assim como obras e documentos oficiais.

\section{O DEBATE DO DESENVOL VIMENTO SUSTENTÁVEL E A AGENDA 2030 DAS NAÇÕES UNIDAS}

A compreensão do desenvolvimento sustentável deve ser realizada, primeiramente, a partir de seus elementos históricos, a fim de compreender, ainda que brevemente, essa complexa trajetória. Desde a Conferência de Cúpula realizada em Estocolmo, em 1972, a preocupação com a questão ambiental do planeta se tornou um importante palco de discussões. A criação da Comissão Mundial sobre o Meio Ambiente e Desenvolvimento Humano, criada pela Assembleia Geral das Nações Unidas, foi resultado dessa preocupação.

A publicação do Relatório de Brundtland, conhecido também como "Nosso Futuro Comum" trouxe o conceito de desenvolvimento sustentável, fornecendo direcionamentos importantes para a Conferência de Cúpula de 1992, realizada no Rio de Janeiro (JAPIASSÚ e GUERRA, 2017). Assim, conforme definição do mencionado relatório, “desenvolvimento que procura satisfazer as necessidades da geração atual, sem comprometer a capacidade das gerações futuras de satisfazerem as suas próprias necessidades" (UNITED NATIONS, 1987).

A Cúpula de 1992, conhecida como Conferência das Nações Unidas sobre Meio Ambiente e Desenvolvimento - Rio 92, reuniu mais de 100 representantes estatais para discutir as gerações futuras o direito ao desenvolvimento. Nesse evento, os países consentiram com a promoção do desenvolvimento sustentável, voltada à preocupação com os seres humanos e com a proteção do meio ambiente, adotando a chamada "Agenda 21", consistente 
em uma carta de intenções destinada a promover, a nível global, um novo padrão de desenvolvimento para o século XXI (ONU, 2015).

Posteriormente, na Rio+20 em 2012, 193 países e membros representantes da sociedade civil, reuniram-se novamente no Rio de Janeiro para avaliar o progresso das ações da Rio-92, do qual foram adotados novos e emergentes desafios. Os principais assuntos dessa conferência foi voltado para a economia verde no âmbito do desenvolvimento sustentável e a erradicação da pobreza. Como resultado, o documento "O Futuro que Queremos" reconheceu que a formulação de metas seria essencial para o lançamento de uma ação global coerente e focada no desenvolvimento sustentável.

Como resultado das discussões de cúpulas anteriores, foram lançados os Objetivos do Milênio (ODM), adotados pelos Estados-membros da ONU no ano de 2000, e consistiam em: erradicar a extrema pobreza e a fome; atingir o ensino básico e universal; promover a igualdade de gênero e a autonomia das mulheres; reduzir a mortalidade infantil; melhorar a saúde materna; combater o HIV/AIDS, a malária e outras doenças; garantir a sustentabilidade ambiental e estabelecer uma parceria mundial para o desenvolvimento (ONU, 2015). Esses objetivos tornaram-se o primeiro arcabouço global de ações destinadas ao desenvolvimento, e contribuíram para a adoção de políticas pelos governos.

Em 2010, realizou-se a Cúpula das Nações Unidas sobre os Objetivos do Milênio, com a finalidade de discutir meios para acelerar a implementação desses objetivos, bem como discutir uma nova agenda de desenvolvimento pós-2015. Com isso, foi implementado um amplo e inclusivo sistema de consulta para questões de interesse global, voltado à construção dos Objetivos de Desenvolvimento Sustentável, que foi construído por muitos participantes e colaboradores (ONU, 2015).

Assim, foi criado o Grupo de Trabalho Aberto para a elaboração dos ODS, encarregado da elaboração de uma proposta para os ODS. Era composto de 70 países e contou com o auxílio de muitos interessados, como contribuições especializadas da sociedade civil, a comunidade científica e o próprio sistema das Nações Unidas. A proposta foi finalizada em 2014 e foi submetida para a Assembleia Geral da ONU no ano de 2015, já com a indicação dos 17 objetivos e das 169 metas que hoje integram a Agenda 2030 (ONU, 2015).

Em 2015, 193 países membros da ONU se reuniram em Nova York, reconhecendo que a erradicação da pobreza em todas as suas formas é o maior desafio global e um requisito indispensável para o desenvolvimento sustentável. Assim, adotaram o documento 
“Transformando o nosso mundo: a Agenda 2030 para o desenvolvimento sustentável”, comprometendo-se a tomar medidas ousadas e transformadoras nos próximos 15 anos (ONU, 2015).

Sob o lema de "não deixar ninguém para trás", a Agenda 2030 configura-se como um novo projeto civilizatório, para as pessoas, o planeta e a prosperidade. Como um ambicioso plano de ação para governos sociedades, empresas e academias, contém então 17 objetivos e 169 metas voltadas à promoção do desenvolvimento sustentável, a serem alcançados até o ano de 2030 pelos países adotantes, com o intuito ainda de fortalecer a paz universal, com o espírito de parceria global que oriente as escolhas necessárias à melhoria da qualidade de vida das pessoas (ONU, 2015).

Os ODS surgem em um contexto que se difere daquele que deu origem os ODM. As transformações dos últimos anos redefiniram a agenda, as condições e o próprio conteúdo do desenvolvimento sustentável, gerando novos arranjos de poder entre os atores. De um lado, há uma redistribuição de poder entre atores estatais, com a ascensão de países emergentes. Esse processo modifica a posição dos atores na hierarquia do sistema. De outro lado, há difusão de poder entre os atores não estatais e sua dispersão em estruturas e mercados, por conta do processo de globalização, fazendo com que os países estejam cada vez mais situados em redes de interdependências. Isso gera a necessidade de maior cooperação entre os Estados (SANAHUJA e VÁZQUEZ, 2016).

Esses aspectos modificaram o contexto da agenda global de desenvolvimento, deixando de ser uma questão enquadrada nas relações Norte-Sul e em políticas de ajuda, mas, sim, consistindo numa agenda universal que influencia políticas nacionais e estilos de vida insustentáveis em vigor tanto nos países desenvolvidos como nos subdesenvolvidos (SANAHUJA e VÁZQUEZ, 2016).

Os objetivos e metas do desenvolvimento sustentável não são uma solução para os problemas existentes nas três dimensões da sustentabilidade. Pelo contrário, sugere uma mudança no comportamento da humanidade, a nível global. Conforme (BARTER e RUSSELL, 2012) o desenvolvimento sustentável não indica apenas medidas para salvar o meio ambiente, mas ele trata da sobrevivência humana e do próprio planeta.

\section{O ACESSO À INFORMAÇÃO ENQUANTO DIREITO HUMANO E FUNDAMENTAL}


O direito à informação é pressuposto fundamental, seja na perspectiva individual como um direito fundamental individual, seja como na seara coletiva, ao garantir a democracia e o exercício da cidadania no Estado Democrático de Direito. Desta forma, o direito à informação é essencial à dignidade da pessoa humana na medida é de vital importância para o desenvolvimento da autonomia do sujeito, além de

Com o passar do tempo foi percebida a necessidade de positivação do direito à informação e com isso, foi consagrado na Constituição Federal de 1988, em seu Artigo $5^{\circ}$, inciso $\mathrm{XIV}^{1}$ (BRASIL, 2020) como sendo um direito fundamental, o qual tem como finalidade a salvaguarda da informação, seja no sentido de acessá-la ou na obrigatoriedade de recebê-la, consolidando-se como um fator indispensável à vida do ser humano e assegurado à todos, sem distinção, de acordo com Felipe da Veiga Dias (2015).

Para que se chegasse nesta atual configuração, Ingo Wolfgang Sarlet (2015), afirma que foi necessária a ruptura estrutural de um Estado autoritário para um Estado de Direito, o que culminou na concepção clássica dos direitos fundamentais, denominados de primeira dimensão ou geração, assumindo relevo as liberdades, sejam elas de informação, expressão, imprensa, manifestação, entre outras.

A consagração da liberdade ocorreu sob a forma de direitos naturais e civis na Constituição Francesa de 1791, de acordo com José Joaquim Gomes Canotilho (2003, p. 394), garantindo a liberdade de ir, permanecer e partir; a liberdade de falar, escrever, imprimir e publicar o pensamento; liberdade de exercer o culto religioso ao qual esteja ligado; a liberdade aos cidadãos de se reunirem pacificamente e sem armas; a liberdade de enviar, às autoridades constituídas, petições assinadas individualmente. Pela perspectiva do constitucionalismo moderno francês, as liberdades individuais são direitos civis em sua essência.

A partir disso, depreende-se que a liberdade (no sentido lato e stricto) é de extremo relevo para a sociedade e para os indivíduos que dela fazem parte. Deste modo, numa

\footnotetext{
${ }^{1}$ Artigo 5': Todos são iguais perante a lei, sem distinção de qualquer natureza, garantindo-se aos brasileiros e aos estrangeiros residentes no país a inviolabilidade do direito à vida, à liberdade, à igualdade, à segurança e à propriedade, nos termos seguintes:

$[\ldots]$

XIV - é assegurado a todos o acesso à informação e resguardado o sigilo da fonte, quando necessário ao exercício profissional.
} 


\section{O ACESSO À INFORMAÇÃO COMO INSTRUMENTO À EDUCAÇÃO INCLUSIVA: UM OLHAR A PARTIR DO DESENVOLVIMENTO SUSTENTÁVEL}

perspectiva kantiana, segundo Sarlet (2015, p. 40): "todos os direitos estão abrangidos pelo direito de liberdade, direito natural por excelência, que cabe a todo homem em virtude de sua própria humanidade e limitado apenas pela liberdade do outro".

Já no final do século XIX, nasceu a dicotomia entre direito individual e direito político e a distinção das funções clássicas dos direitos fundamentais na relação entre o particular e o Estado foi feita por Georg Jellinek por meio dos conceitos de status ${ }^{2}$ negativus, status passivo $^{3}$, status positivus ${ }^{4}$ e status activus ${ }^{5}$. Segundo Bodo Pieroth e Bernhard Schlink (2012, p. 16) o status negativus é o estado de liberdade em frente ao Estado, ou seja, quando o particular possui autonomia para determinar as suas escolhas sem a interferência dos poderes públicos. Este status é assegurado pelos direitos fundamentais, como direitos de defesa, protegendo liberdades ou bens contra o Estado.

Desta forma, como resultado da democratização das relações de poder, pode ser identificada a existência de um "direito humano ao saber", de acordo com Sarlet (2014), resultado das liberdades públicas que foram conquistadas no processo civilizatório. A liberdade de expressão, tendo como correlato o direito à informação, além de ser um direito humano fundamental imprescindível, representa técnica democrática nas relações humanas, no âmbito público e particular e que pode ser chamado também, em um contexto geral de Direito da Informação (SARLET, 2014).

O direito da informação é o resultado de interações socioculturais que ao longo do tempo formataram a comunicação social, sendo produzido por um conjunto de mandamentos políticos, sociais e morais, que resultaram em um conjunto de normas jurídicas regulatórias e disciplinadoras daquelas relações. É um segmento do direito o qual podemos chamar de direito das "relações informativas" (SARLET, 2014), vez que abarca a liberdade de

\footnotetext{
${ }^{2}$ O status nada mais é que a situação do particular frente ao Estado, de modo a garantir seus direitos fundamentais, ou seja, uma relação com o Estado que qualifica o indivíduo.

${ }^{3}$ O status passivo, de acordo com Robert Alexy (p. 256, 2017) dá ensejo a duas interpretações. A primeira diz respeito a existência de algum dever ou proibição estatal ao qual o indivíduo está sujeito, ou seja, que o Estado teria uma competência diante do indivíduo para estabelecer algum dever ou proibição que o afetasse. Já a segunda, o status de uma pessoa é composto pelos deveres e proibições que o Estado lhe impõe ou que tem competência para a imposição.

${ }^{4} \mathrm{O}$ status positivus corresponde ao estado em que o particular depende do Estado para exercer a sua liberdade, ou seja, depende de medidas do Estado para o desenvolvimento e conservação da sua existência livre, quando o Estado assegura ao particular o seu direito à participação, proteção, reivindicação, entre outros.

${ }^{5} \mathrm{O}$ status activus é quando o particular exerce a sua liberdade no e para o Estado, auxiliando a construção e participação neste. Configura-se pelo exercício dos direitos cívicos. Exemplo claro deste status é quando o indivíduo possui o direito de votar e ser votado, exercendo, assim, a sua liberdade.
}

\section{Revista de Direito, Governança e Novas Tecnologias | e-ISSN: 2526-0049 | Encontro} Virtual | v. 6 | n. 2 | p. 65 - 81 | Jul/Dez. 2020. 
informação, os direitos à informação e o direito ao acesso à informação em face dos órgãos estatais.

No que toca ao cerne do presente estudo, qual seja, o direito humano e fundamental ao acesso à informação, cuida-se de desdobramento do direito à informação, além da própria liberdade de expressão e comunicação, o qual assume uma função de cláusula geral para as diversas liberdades comunicativas, conforme Jónatas E. M. Machado (2002) como é o caso da liberdade religiosa, liberdade artística, liberdade de reunião e de manifestação, liberdade de comunicação social (mídia), liberdade de ensino e pesquisa, bem como a liberdade de informação.

No âmbito do direito constitucional brasileiro, o direito da informação encontra guarida no dever do Estado de promover, apoiar e incentivar o desenvolvimento científico, a pesquisa e a capacitação tecnológica, de acordo com o Artigo 218 (BRASIL, 2020) ${ }^{6}$. De acordo com Sarlet (2014), os deveres do Estado com o desenvolvimento científico e investigação tecnológica estão bem definidos no texto constitucional, principalmente no que se refere ao plano nacional da educação, especialmente da promoção humanística, científica e

\footnotetext{
${ }^{6}$ Art. 218. O Estado promoverá e incentivará o desenvolvimento científico, a pesquisa, a capacitação científica e tecnológica e a inovação.

$\S \mathbf{1}^{\mathbf{0}}$ A pesquisa científica básica e tecnológica receberá tratamento prioritário do Estado, tendo em vista o bem público e o progresso da ciência, tecnologia e inovação.

$\$ 2^{\circ}$ A pesquisa tecnológica voltar-se-á preponderantemente para a solução dos problemas brasileiros e para o desenvolvimento do sistema produtivo nacional e regional.

§ $3^{\circ}$ O Estado apoiará a formação de recursos humanos nas áreas de ciência, pesquisa, tecnologia e inovação, inclusive por meio do apoio às atividades de extensão tecnológica, e concederá aos que delas se ocupem meios e condições especiais de trabalho.

\$ $4^{\circ}$ A lei apoiará e estimulará as empresas que invistam em pesquisa, criação de tecnologia adequada ao País, formação e aperfeiçoamento de seus recursos humanos e que pratiquem sistemas de remuneração que assegurem ao empregado, desvinculada do salário, participação nos ganhos econômicos resultantes da produtividade de seu trabalho.

§ $5^{\circ}$ É facultado aos Estados e ao Distrito Federal vincular parcela de sua receita orçamentária a entidades públicas de fomento ao ensino e à pesquisa científica e tecnológica.

§ $6^{\circ}$ O Estado, na execução das atividades previstas no caput, estimulará a articulação entre entes, tanto públicos quanto privados, nas diversas esferas de governo.

$\$ 7^{\circ} \mathrm{O}$ Estado promoverá e incentivará a atuação no exterior das instituições públicas de ciência, tecnologia e inovação, com vistas à execução das atividades previstas no caput.
} 
tecnológica do país, conforme Artigo 214, IV ${ }^{7}$ (BRASIL, 2020), sem descuidar do Artigo 5, inciso XIV anteriormente citado..

Numa perspectiva jurídica internacional, é possível verificar a proteção à informação assegurada em importantes documentos internacionais, como por exemplo na Declaração Universal dos Direitos Humanos (2020), em seu Artigo XIX, o qual assegura que "toda pessoa tem direito à liberdade de opinião e expressão; este direito inclui a liberdade de, sem interferência, ter opiniões e procurar, receber e transmitir informações e ideias por quaisquer meios e independentemente de fronteiras".

Assim, é possível perceber que o ordenamento jurídico nacional e internacional afirmam a necessidade da livre profusão das ideias, consagrando a informação, no sentido amplo, como sendo um direito fundamental, além de correlacioná-la com outros direitos fundamentais, como a educação, cuja garantia e acesso pleno vem sendo influenciada pelo acesso à informação.

A informação gera capacidades de formalizar conhecimentos, além de constituir um empoderamento para a construção de uma cidadania consciente, e contribuir para um desenvolvimento sustentável. Nesse sentido, o tema é de relevância atual, especialmente pelas mudanças provocadas pelo "novo normal" e a necessidade da utilização de instrumentos tecnológicos como requisito para se ter acesso à educação em tempos de pandemia em que todas as atividades de ensino passaram a ser ministrada por meio do ensino remoto e on-line. E este é o ponto nevrálgico do presente estudo, eis que a informação, conforme será verificado, é pressuposto fundamental para a concretização dos saberes.

\section{O ACESSO À INFORMAÇÃO COMO INSTRUMENTO AO ALCANCE DA EDUCAÇÃO INCLUSIVA}

\footnotetext{
${ }^{7}$ Art. 214. A lei estabelecerá o plano nacional de educação, de duração plurianual, visando à articulação e ao desenvolvimento do ensino em seus diversos níveis e à integração das ações do poder público que conduzam à:

I - erradicação do analfabetismo;

II - universalização do atendimento escolar;

III - melhoria da qualidade do ensino;

IV - formação para o trabalho;

V - promoção humanística, científica e tecnológica do País.
} 
O acesso à informação possibilita que o indivíduo alcance sua autonomia, e que as suas intervenções na sociedade ocorram com base em dados conhecidos e sob a análise de um esclarecimento anterior. Por meio dele, há uma consciência dos acontecimentos, passando a ser um agente necessário à efetivação de uma participação e, consequentemente, da democracia, concordando-se ou discordando-se das ações proferidas pelos diversos entes (GOMES, 2016).

Nesse viés, esse acesso à informação está intrinsecamente relacionado à Agenda 2030 das Nações Unidas, principalmente no que se refere ao seu quarto objetivo, educação, em que estão dispostas sete metas. O seu alcance está focado em tornar a educação de qualidade, inclusiva e equitativa, com a ampliação de meios de aprendizagem e conhecimento para todos, com base nos princípios de direitos humanos e desenvolvimento sustentável, e como uma indutora necessária às diversas mudanças propostas (ORGANIZAÇÃO DAS NAÇÕES UNIDAS, 2015).

Ela contempla uma formação pautada no desenvolvimento sustentável em toda a sua pluridimensionalidade, buscando construir uma educação de qualidade, em ambientes seguros de aprendizagem, inclusivos e eficazes, com valores calcados na democracia, na promoção de um cidadão, reduzindo-se as desigualdades (QUEIROZ, 2017).

Assim, conforme o ODS n. 4, busca-se, até o ano de 2030, além de outras disposições, garantir uma educação de qualidade e justa que ofereça uma inclusão, seja ela digital, social, a fim de que seja proporcionado a todos os indivíduos oportunidades de aprendizagem ao longo da vida (CASTRO FILHO, 2018).

A educação inclusiva, dessa forma, refere-se a uma educação que abarca e reconhece a diversidade, principalmente as diferenças individuais, e que seja de qualidade. A inclusão se encontra pautada em princípios de igualdade e diversidade, bem como nos valores de uma sociedade democrática e justa. Ademais, para que a educação seja inclusiva o seu acesso deve ser a todos garantido, respeitando as diferenças dos alunos e realizando o atendimento às suas necessidades educativas. Isso implica adaptações para com as necessidades individuais de aprendizagem de cada um (TEZANI, 2009).

O ambiente educacional deve se dar em um local favorável, disponível aos indivíduos, em que o clima organizacional possa contribuir para o saber e a cultura, sendo as diferenças consideradas no processo de ensino-aprendizagem autônomo e emancipatório, a 
fim de possibilitar o desenvolvimento de conhecimentos sociais, políticos, éticos, entre outros (TEZANI, 2009).

Assim, o acesso à informação, possibilitando o alcance do conhecimento, torna-se instrumento de uma educação inclusiva, em que há um fortalecimento do relacionamento entre os indivíduos na sua diversidade e com o mundo, da consciência pelas responsabilidades assumidas no efetivo exercício da cidadania e no enfrentamento das problemáticas cotidianas, sendo a educação primordial nesse processo, além de fomentar uma reflexão e criticidade (BELLUZZO, 2018).

Barros (2017) expõe que os aspectos que perpassam a era informacional, como a promoção do acesso à informação, resultam benefícios em diversos campos de atuação da sociedade, difundindo ideias que permitem a efetivação de objetivos que cercam interesses em âmbito global, como é o caso da educação.

A informação é considerada como fator predominante para o desenvolvimento social, econômico e cultural e constitui o principal elemento para a construção do conhecimento. Em decorrência, o acesso à informação é decisivo para o aprimoramento do indivíduo, assim como da comunidade da qual ele faz parte, possibilitando que uma educação inclusiva seja concretizada (BELLUZZO, 2018). Nesse viés, o indivíduo, tornando-se tutor das informações e conhecimentos, permite que a educação ocorra a todos, atuando não somente no processo de aprendizagem, mas também de ensino (DRAVET; CASTRO, 2019).

A garantia do direito de acesso à informação é uma ferramenta proporcionadora de diversos direitos do homem, sendo um deles a educação, salvaguardada por diversos organismos internacionais. É um instituto que fortalece uma participação na sociedade, principalmente como um meio de controle social das políticas implementadas pelos governos, além de fomentar com que os indivíduos participem da formulação de políticas de educação e efetivação, em um processo de cidadania. Assim, proporciona maior difusão do conhecimento sobre os saberes e as suas práticas (BARRETTO NETO; MENEZES, 2018).

O relatório para Organização das Nações Unidas para a Educação, a Ciência e a Cultura - UNESCO, da Comissão Internacional sobre Educação para o século XXI, aponta que a educação deve organizar-se em quatro pilares fundamentais do conhecimento, que são o aprender a conhecer, que sinteticamente significa obter ferramentas para a compreensão; aprender a fazer, a fim de possibilitar atitudes acerca do meio em que vive o indivíduo; aprender a viver juntos, estabelecido com o intuito de colaborar com os demais indivíduos em 
suas ações; e por fim o aprender a ser, que em resumo abrange os pilares já expostos (DELORS et al, 2003).

Nessa concepção, a informação colabora para que haja uma concretização dos saberes, auxiliando que as ações sejam realizadas de forma construtiva, em um pensar-fazer, com indivíduos dinamizados, atuantes, críticos e cooperativos, participando da sociedade com o intuito de minimizar, no caso da educação inclusiva, as suas barreiras.

$\mathrm{O}$ acesso à informação, como instrumento de conhecimento e consequentemente de uma educação inclusiva, possibilita que:

[...] se ultrapasse a visão puramente instrumental da educação, considerada como a via obrigatória para obter certos resultados (saber-fazer, aquisição de capacidades diversas, fins de ordem econômica), e se passe a considerá-la em toda a sua plenitude: realização da pessoa que, na sua totalidade, aprende a ser. (DELORS et al, 2003, p. 90).

Diante disso, permite-se desenvolver aos indivíduos modificações nos seus valores, transformações das atitudes em relação ao conhecimento e ao domínio do saber. Educar o indivíduo, portanto, sem retirá-lo do seu contexto histórico e social, devendo ser afastado um processo de ensino-aprendizagem enciclopédico e permanente, havendo a necessidade de que a educação ocorra de forma substancial, com o desenvolvimento de um saber-ser, saber-fazer, saber-aprender e saber-estar, estando ela permeada por tecnologia, arte, ciência, ecologia, entre outros, possibilitando uma educação inclusiva, que reconhece a diversidade na escola, garantindo o acesso a todos, independentemente de diferenças individuais (BELLUZZO, 2018).

Ademais, a disseminação da informação e de uma conexão global têm grande potencial para acelerar o progresso humano, para suprimir barreiras e desenvolver uma sociedade do conhecimento, em que em meio à inovação científica e tecnológica, a educação seja preponderante, e esteja acessível a todos (ORGANIZAÇÃO DAS NAÇÕES UNIDAS, 2015).

Por meio de uma troca de experiências, informações, conhecimentos, a educação é possibilitada, conforme compreende a Agenda 2030 da ONU, principalmente quando se refere ao seu sentido colaborativo dos países, a fim de que participem da iniciativa em prol de um bem comum (CASTRO FILHO, 2018). 
Nota-se, assim, a relevância do direito de acesso às informações como ferramenta de fortalecimento da difusão do conhecimento, na perspectiva de garantir para os cidadãos outros direitos fundamentais, como ocorre com a educação, bem como salienta-se a possibilidade do acompanhamento das políticas públicas, visando à tomada de decisões que favoreçam o desenvolvimento sustentável (BARRETTO NETO; MENEZES, 2018).

A informação como instrumento de uma educação inclusiva gera capacidades de formalizar conhecimentos e inovação, constitui ao mesmo tempo um empoderamento informacional, enfatizando em tal processo a ideia de desenvolvimento disposta na Agenda 2030 da ONU (GERBASI, 2017). Contribui-se, ainda, para a construção de uma cidadania consciente, além de dever estimular a criação, produção e circulação de novos conteúdos originais no entorno onde se insere, contribuindo para um desenvolvimento sustentável, memória coletiva e patrimônio cultural da sociedade (BELLUZZO, 2018).

O acesso e uso da informação para a construção de conhecimento e sua aplicação a uma realidade coaduna com a concretização da educação inclusiva disposta no ODS n. 4 da Agenda 2030 da ONU (BELLUZZO, 2018). Embasada em um formato de aprendizagem independente e com soluções inovadoras para um desenvolvimento sustentável, possibilita que haja uma mudança aos passos até então seguidos, a fim de que o equilíbrio entre a questão econômica, a preservação do meio ambiente e o desenvolvimento social e institucional seja concretizado (MOTA; OLIVEIRA, 2014).

\section{CONCLUSÃO}

O presente estudo versou sobre a educação inclusiva, pautada principalmente no acesso à informação e no desenvolvimento sustentável, sendo este último aspecto vislumbrado na Agenda 2030 da ONU.

Como exposto, a Agenda 2030 propõe um diálogo entre as mais diversas instituições e sociedade, unindo o desenvolvimento e a sustentabilidade pluridimensional. Ela sugere uma alteração nas ações dos indivíduos em nível global, assim como influência nas políticas desenvolvidas pelos Estados.

Nesse sentido, o acesso à informação é um dos diversos pressupostos para a efetivação da Agenda 2030. Afinal, encontra-se como garantidor de uma democracia e 
exercício de cidadania em um Estado Democrático de Direito, diante da profusão de ideias e de conhecimentos. Ele aproxima os indivíduos e oportuniza a propagação de diversas culturas, dando contextualizadas significações aos processos de ensino e aprendizagem.

Diante disso, o acesso à informação é eficaz para a obtenção de conhecimento. Ele contribui para que a educação não ocorra de maneira isolada, abarcando diversas áreas do conhecimento, desenvolvendo formas de cultura participativa.

A Agenda 2030, através do seu quarto objetivo de educação, expõe uma educação inclusiva que pode ser alcançada por meio do acesso à informação, diante do fortalecimento do relacionamento entre os indivíduos na sua diversidade e com o mundo, da consciência pelas responsabilidades assumidas no efetivo exercício da cidadania e no enfrentamento das problemáticas cotidianas.

Ante a disposição do estudo, a informação colabora para que haja uma concretização dos saberes a todos os indivíduos, observando-se um equilíbrio entre a questão econômica, a preservação do meio ambiente e o desenvolvimento social e institucional. Portanto, ficou compreendido que o acesso à informação pode desempenhar um papel relevante para a efetivação da educação inclusiva presente como um objetivo da Agenda 2030 da ONU.

\section{REFERÊNCIAS}

BARRETO NETO, José Francisco; MENEZES, Ana Maria Ferreira. O acesso à informação e a difusão do conhecimento no fortalecimento da política de educação profissional da Bahia. BA\&D - Bahia Análise de Dados, v. 28, n. 1, p. 93-109, 2018. Disponível em: http://publicacoes.sei.ba.gov.br/index.php/bahiaanaliseedados/article/. Acesso em: 25 set. 2020 .

BARROS, Lucivaldo Vasconcelos. Sustentabilidade Ambiental e direito de acesso à verdade: de Estocolmo aos dias atuais. Revista Brasileira de Biblioteconomia e Documentação, Fortaleza, v. 13, n. 1, p.2923-2940, jan. 2017. Disponível em: https://rbbd.febab.org.br/rbbd/article/view/860. Acesso em: 20 maio 2019.

BARTER, Nick; RUSSELL, Sally. Sustainable Development: 1987 to 2012 - Don't Be Naive, it's not about the Environment. In: 11TH AUSTRALASIAN CONFERENCE ON SOCIAL AND ENVIRONMENTAL ACCOUNTING RESEARCH (A-CSEAR). Proceedings... University of Wollongong, 2012. p. 1-18. 
BELLUZZO, Regina Celia Baptista. Competência em informação (CoInfo) e midiática: interrelação com a Agenda 2030 e os Objetivos de Desenvolvimento Sustentável (ODS) sob a ótica da educação contemporânea. Pesquisa Brasileira em Ciência da Informação e Biblioteconomia, v. 13, n. 2, p. 15-24, 2018. Disponível em: https://periodicos.ufca.edu.br/ojs/index.php/folhaderosto/article/view/289. Acesso em: 25 set. 2020.

BRASIL, República Federativa do. Constituição Federal de 1988. Disponível em: http://www.planalto.gov.br/ccivil_03/constituicao/constituicao.htm. Acesso em: 03 jul. 2020.

CANOTILHO, José Joaquim Gomes. Direito Constitucional e Teoria da Constituição. São Paulo: Saraiva, 2003.

CASTRO FILHO, Claudio Marcondes de. The 2030 agenda for sustainable development: A reading of public policy in the key of the school library. Revista Digital de Biblioteconomia e Ciencia da Informacao, v. 16, n. 3, p. 355-372, 2018. Disponível em: https://periodicos.sbu.unicamp.br/ojs/index.php/rdbci/article/download/8650931/pdf_1/. Acesso em: 26 set. 2020.

DRAVET, Florence; CASTRO, Gustavo de. Aprendizagem, meios digitais e afeto: propostas para um novo paradigma na educação superior. Interface - Comunicação, Saúde, Educação, v. 23, p. 1-14, 2019. Disponível em: https://www.scielo.br/pdf/icse/v23/1807-5762-icse-23e180321.pdf. Acesso em: 20 maio 2020.

DELORS, Jacques et al. Educação: um tesouro a descobrir. 9. ed. São Paulo: Cortez, 2004.

DECLARAÇÃO UNIVERSAL DOS DIREITOS HUMANOS. Declaração Universal dos Direitos Humanos. Disponível em:

http://www.dhnet.org.br/direitos/deconu/textos/integra.htm. Acesso em: 01 jul. 2020

DIAS, Felipe da Veiga. O direito fundamental da criança e do adolescente à informação e às políticas públicas de comunicação preventivas e protetivas de conteúdo adulto na internet no Brasil. Tese. (Doutorado) - Programa de Pós Graduação em Direito, Universidade de Santa Cruz do Sul, Santa Cruz do Sul, 2015.

GERBASI, Vinicius Aleixo. Sociedade da informação: a lógica instrumental do acesso à informação e ao conhecimento. Informação em Pauta, v. 2, n. 1, p. 96-118, 2017.

Disponsível em: http://www.periodicos.ufc.br/informacaoempauta/article/view/11721. Acesso em: 25 set. 2020.

GOMES, Amanda. Lei de acesso á informação: o cidadão enquanto sujeito informativo. Pesquisa Brasileira em Ciência da Informação e Biblioteconomia, v. 12, n. 2, p. 5-21, 2017. Disponível em: https://periodicos.ufpb.br/index.php/pbcib/article/view/36542. Acesso em 25 set. 2020.

JAPIASSÚ, Carlos Eduardo; GUERRA, Isabella Franco. 30 Anos do Relatório Brundtland: nosso futuro comum e o desenvolvimento sustentável como diretriz constitucional brasileira.

Revista de Direito, Governança e Novas Tecnologias | e-ISSN: 2526-0049 | Encontro Virtual | v. 6 | n. 2 | p. 65 - 81 | Jul/Dez. 2020. 
Revista de Direito da Cidade, [S.L.], v. 9, n. 4, p. 1884-1901, 23 out. 2017. Universidade de Estado do Rio de Janeiro. http://dx.doi.org/10.12957/rdc.2017.30287.

MACHADO, Jónatas E. M. Liberdade de Expressão: Dimensões Constitucionais da Esfera Pública no Sistema Social. Coimbra: Coimbra Editora, 2002.

MOTA, Ronaldo; OLIVEIRA, João F. G. Inovação e sustentabilidade: paradigma educacional para o desenvolvimento. Abmes Cadernos - Desafios da educação num mundo globalizado e sem fronteiras, v. 28, 2014, p. 10. Disponível em: https://abmes.org.br/arquivos/publicacoes/abmes_cadernos_28.pdf. Acesso em: 18 maio 2020.

ORGANIZAÇÃO DAS NAÇÕES UNIDAS. Transformando nosso mundo: A Agenda 2030 para o desenvolvimento sustentável. Disponível em: https://nacoesunidas.org/wpcontent/uploads/2015/10/agenda2030-pt-br.pdf. Acesso em: 25 ago. 2020.

Conheça a Agenda 2030: conheça o plano de ação global para mudar o mundo até 2030. Disponível em: http://www.agenda2030.com.br/sobre/. Acesso em: 27 set. 2020.

PIEROTH, Bodo; SCHLINK, Bernhard. Direitos Fundamentais. São Paulo: Saraiva, 2012.

QUEIROZ, Isaac Newton Lucena Fernandes de et al. Educação e Etnociência: caminhos da agenda 2030 para o desenvolvimento sustentável. Revista Ibero-Americana de Ciências Ambientais, v. 8, n. 2, p. 253, 2017. Disponível em: https://sustenere.co/index.php/rica/article/view/SPC2179-6858.2017.002.0020/846. Acesso em: 02 jun. 2020.

SARLET, Ingo Wolfgang. A eficácia dos Direitos Fundamentais: uma teoria geral dos direitos fundamentais na perspectiva constitucional. Porto Alegre: Livraria do Advogado, 2015 .

SARLET, Ingo Wolfgang; MOLINARO, Carlos Alberto. Direito à informação e direito de acesso à informação como direitos fundamentais na constituição brasileira. Disponível em: https://repositorio.pucrs.br/dspace/bitstream/10923/11403/2/Direito_a_768_Informac_807_a_ 771_o_e_Direito_de_Acesso_a_768_Informac_807_a_771_o_como_Direitos_Fundamentais_ na.pdf. Acesso em: 25 set. 2020.

TEZANI, Thaís Cristina Rodrigues. A relação entre gestão escolar e educação inclusiva: o que dizem os documentos oficiais? Revista on line de Política e Gestão Educacional, n. 6, p. 1-21, 2009. Disponível em: https://periodicos.fclar.unesp.br/rpge/article/view/9249. Acesso em 25 set. 2020 .

UNITED NATIONS. Our Common Future. 1987. Disponível em: https://sustainabledevelopment.un.org/content/documents/5987our-common-future.pdf. Acesso em: 25 ago. 2020.

VÁZQUEZ, Sergio Tezanos; SANAHUJA, José Antonio. Del milenio a la sostenibilidad":: retos y perspectivas de la agenda 2030 para el desarrollo sostenible. Política y Sociedad, 
[S.L.], v. 54, n. 2, p. 521-543, 2 out. 2017. Universidad Complutense de Madrid (UCM). http://dx.doi.org/10.5209/poso.51926. 